\title{
R-MPV Regimen
}

National Cancer Institute

\section{Source}

National Cancer Institute. R-MPV Regimen. NCI Thesaurus. Code C140109.

A regimen consisting of rituximab, methotrexate, procarbazine and vincristine that can be used in the treatment of central nervous system (CNS) lymphoma. 